\title{
Racionalidade e Organização: as Múltiplas Faces do Enigma
}

\author{
Rationality and Organization: \\ the Multiple Aspects of an Enigma
}

Victor Natanael Schwetter Silveira*

Mestre em Administração pela UFMG.

Professor na FNH, Belo Horizonte/MG, Brasil.

*Endereço: Rua Curitiba, 832, sala 1105, Centro, Belo Horizonte/MG, 30170-120. E-mail: victornss@uai.com.br 


\section{Resumo}

Este artigo estabelece uma discussão teórica acerca do conceito de racionalidade e seus impactos no campo da teoria das organizações. Inicialmente, são abordadas algumas influências filosóficas sobre as idéias de razão e racionalidade, a partir de um breve resgate histórico e filosófico da dualidade entre as concepções de lógica (pensamento) e pragmática (ação). Em seguida a racionalidade é discutida com base na perspectiva weberiana, e sua teoria burocrática. São considerados depois os limites cognitivos da racionalidade e na seção final do texto são brevemente discutidas as relações entre racionalidade, legitimidade e institucionalização. Finalmente, a racionalidade é abordada a partir da perspectiva da Teoria Crítica, com autores como Habermas (1987a) Horkheimer (2002) e Marcuse (1975). Essa discussão busca apontar a abrangência e os múltiplos aspectos da racionalidade implicados na relação indivíduo-organização, fornecendo subsídios para avançar o debate sobre a noção de racionalidade no campo da teoria organizacional.

Palavras-chave: racionalidade; burocracia; legitimidade; institucionalização; sentido compartilhado.

\section{Abstract}

The aim of this article is to make a theoretical discussion about the rationality concept and its impacts over the organization's context. Starting from the philosophical influences by notions of reason and rationality, a brief historical and philosophical approach is making, discussing about the duality of two basics notions: logic (thought) and pragmatic (action). On sequence, the rationality concept it's considered with regard to Weber's theory of bureaucracy. After that, the cognitive boundaries of human rationality are considered and the relationships between rationality, legitimacy and institutionalization are overviewed. Finally, rationality is overviewed based on Critical Theory authors like Habermas (1987a), Horkheimer (2002) and Marcuse (1975). In conclusion, this discussion tries to evidence the range and implications of the multiple facets of rationality concept and also brings concepts to go forward the debates about rationality on organizational theory field.

Key words: rationality; bureaucracy; legitimacy; institutionalization shared sense. 


\section{INTRODUÇÃO}

A partir de meados do século XIX e início do século XX surgiram diversas abordagens teóricas baseadas na lógica e na racionalidade. Tais abordagens se desenvolveram como resultado de um encadeamento histórico que convergiu para a aplicação da idéia de racionalidade em várias áreas do conhecimento humano.

Prevalecia, neste período, o conceito fundamental de racionalidade como a base da prosperidade e da ordem (Spencer \& Barros, 1993). Surgiam, em consequiência, tentativas de aplicar ao estudo das organizações métodos dotados de rigor lógico, objetividade e eficiência.

Observa-se que essa busca por racionalizar as organizações estava em consonância com a expansão capitalista, que promovia o aumento no tamanho das organizações e incentivava o desenvolvimento industrial. Este, por sua vez, requeria mecanismos e técnicas para viabilizar e administrar o trabalho coletivo em organizações maiores e mais complexas, submetendo os indivíduos a uma ordem superior que buscava, em sua instância final, o controle produtivo e a ampliação de lucros. Desse modo, as organizações viram-se diante da necessidade de planejar suas ações e adotar processos lógicos de tomada de decisão e controle do homem no ambiente de trabalho. Esta concepção implicava tornar o comportamento humano intencionalmente racional, inserindo-se aí a compreensão de que uma tarefa primordial a ser desenvolvida pelas organizações, a partir de então, seria regular e modular os aspectos racionais dos indivíduos e coletividades, a fim de obter-se a eficiência e, em última instância, a ordem e a estabilidade social (Spencer \& Barros, 1993).

Diante da necessidade de regular a racionalidade no âmbito das organizações, Weber (1994) elaborou uma teoria e um modelo de estrutura social formal, racionalmente organizada com normas e papéis claramente definidos conhecida como burocracia. Sua abordagem compreendia também, o desenho racional de atividades em função dos propósitos organizacionais, buscado eliminar as disfunções promovidas pela ausência de uma racionalidade objetiva nas empresas. A teoria de Weber influenciou decisivamente o campo de estudo da teoria das organizações a partir de então.

No decorrer do século XX o campo da teoria das organizações recebeu novos aportes teóricos, o que enriqueceu e ampliou a compreensão do fenômeno da racionalidade. Dessa forma, diversos autores voltaram a sua atenção para o exame dos elementos psicológicos, relacionais, contextuais e culturais os quais, dinamicamente, influenciavam os indivíduos e a organização, modelando e 
sustentando sua estrutura, suas ações e sua relação com diversos aspectos da racionalidade. Nessas teorias o conceito de racionalidade voltou a ser reconsiderado e discutido, adquirindo uma dimensão simbólica que até então não dispunha.

Observa-se que o tema da racionalidade no campo da teoria das organizações apresenta-se como um tema de significativa relevância teórica e prática e que, ao mesmo tempo, mostra-se como campo de estudos multifacetado e portador de complexidades inerentes. Buscar uma compreensão mais ampla da idéia de racionalidade no âmbito das teorias organizacionais permite uma aproximação do entendimento da complexa rede de variáveis que configuram a ação e o sentido que os indivíduos estruturam nas organizações.

Retomar o debate da racionalidade torna-se relevante no contexto atual em função da necessidade de revisão de significados e referenciais de ação no campo da teoria das organizações, diante das demandas contemporâneas em aliar a racionalidade às questões contingenciais pelas quais as organizações passam como, por exemplo, a crescente busca de eficiência e controle, a obtenção de vantagens competitivas e o comprometimento dos indivíduos - buscando tecer novas lógicas e estratégias em conformidade, tanto com a prática e com os condicionantes do mundo real, quanto com teorias que re-significam e reconstroem o sentido dos limites humanos, das incertezas e dos determinantes culturais e sociais nas concepções e na vida das organizações.

Este estudo aborda de forma teórica e breve alguns aspectos relevantes ao conceito e prática da noção de racionalidade no contexto das organizações, descrevendo sucintamente as principais implicações e facetas desse conceito no meio organizacional, especialmente em relação ao modelo burocrático de Weber (1994), partindo, inicialmente, de um resgate das bases filosóficas de concepções como razão, racionalidade, lógica e pragmatismo.

\section{Bases Filosóficas da Racionalidade}

Segundo Spencer e Barros (1993) o conceito de razão (lógica) designa uma entidade absoluta e dogmática, que está na base dos grandes sistemas do racionalismo clássico, e que busca alcançar o Absoluto ou a Totalidade do mundo e da natureza. A razão adota a crença na Razão Absoluta que conduz à convicção da existência de um mundo racional, governado por leis inflexíveis definitivamente conhecidas, seja no plano da natureza, seja no da história, acessíveis pelo pensamento lógico. Assim, a razão pressupõe que só é real o que é racional.

No decorrer dos séculos XIX e XX a idéia de razão foi sucedida pela idéia de racionalidade, de caráter pragmático, que designa a atividade metódica e 
sistemática, mas submissa ao real e aos fatos, que, a partir de uma inteligência crítica, busca, permanentemente, identificar e propor reparos, revisões e refutações na tentativa de compreender o mundo e a natureza (Spencer \& Barros, 1993).

Resgatando as bases filosóficas da Antigüidade, observa-se que na tradição filosófica grega prevaleceu a concepção de que a lógica seria o princípio utilizado para se definir a razão. O logos era concebido como a expressão da perfeição, através do pensamento humano. O pensar era, portanto, o reflexo da essência do Ser e constituía uma entidade suficiente para a compreensão do mundo (Luce, 1994; Spencer \& Barros, 1993).

A concepção de lógica se opunha à ação prática, ou seja, era contrária à ação no mundo, à experimentação e às coisas observáveis; estas eram consideradas apenas ilusões produzidas pela percepção humana e, portanto, sujeita a falhas, não podendo servir de base para fundamentar a razão humana. A verdade e a realidade só poderiam ser captadas pelo mundo das idéias, pelo racional puro ou logos.

A prevalência do logos como fundamento da razão humana poder ser vista na obra de alguns importantes filósofos gregos da Antigüidade. Na concepção de Heráclito (cerca de 540-470 a.C.) o princípio unificador que governa o mundo é o logos. Ele estabeleceu a existência de uma lei universal e fixa, regente de todos os acontecimentos particulares e fundamento da harmonia universal. A unidade da variedade infinita dos fenômenos é feita pela tensão oposta dos contrários, ou seja, tudo se faz por contraste (Luce, 1994; Spencer \& Barros, 1993). Desta forma, defendia a existência de uma unidade indiferenciável entre a razão e a ação, ambos constituindo o ser de forma indivisível.

Parmênides (cerca de 530-460 a.C.), por sua vez, representa o oposto ao pensamento humano de Heráclito. Para ele o pensar puro do Ser é o único elemento que pode trazer o conhecimento e a compreensão do mundo (Luce, 1994; Spencer \& Barros, 1993).

Platão (cerca de 428-348 a.C.), seguindo a visão de Parmênides, defendia que as palavras não possibilitam o acesso à verdade, pois elas não têm um autêntico significado cognitivo. A alma necessita, então, estabelecer uma relação direta com o mundo das essências. O modo de verdade se coloca em relação ao grau e à veracidade com que se consegue explicitar o modelo original que só existe no mundo das idéias (Luce, 1994).

Na visão de Aristóteles (384-322 a.C.) a lógica é o estudo sistemático da estrutura das proposições e das condições gerais de inferências válidas, através de um método que abstrai o conteúdo da proposição e se preocupa unicamente com sua forma. Segundo Aristóteles, o raciocínio dedutivo reduz-se essencialmente ao que se denomina silogismo (Luce, 1994). Os componentes do silogismo aristotélico 
são sentenças universais ou particulares, afirmativas ou negativas, isto é, dos tipos seguintes: a) todos os animais são mortais (universal afirmativa); b) nenhum animal é imortal (universal negativa).

Ainda na Antigüidade, a lógica desenvolvida pela Escola dos Estóicos e Megáricos — com Euclides de Megara (cerca de 450-380 a.C.) foi um avanço na concepção lógica de Aristóteles, na medida em que estabeleceu um padrão de lógica baseada no que hoje se denomina Cálculo de Predicados, ou seja, um sistema no qual as proposições (ou sentenças) são desmembradas em seus componentes, ou, consideradas como variáveis a serem relacionadas logicamente (Luce, 1994). A partir daí, são utilizados quantificadores que expressam relações entre conjuntos designados pelas classes de atributos. Os quantificadores mais comuns são: todo, algum e nenhum. Observa-se que aqui o valor-verdade (verdadeiro ou falso) de uma proposição não é necessariamente conhecido, como, por exemplo, nos enunciados: todos os homens são mortais. Sócrates é um homem. Portanto, Sócrates é mortal.

Já na Idade Moderna, no século XVII, o filósofo e matemático alemão Gottfried Wilhelm Leibniz (1646-1716) lançou as bases da lógica moderna, ao tentar dotar a filosofia, em seu aspecto metafísico, de um instrumento suficientemente poderoso que lhe permitisse alcançar o mesmo grau de rigor que tinha alcançado a Matemática. Parecia a Leibiniz que o problema das polêmicas não resolvidas nas discussões filosóficas, assim como a insegurança dos resultados, eram fundamentalmente devidos à ambigüidade dos termos e dos processos conclusivos da linguagem ordinária ou comum. Leibniz, assim, tentou elaborar sua nova lógica, precisamente como um projeto de criação de uma linguagem racional simbólica e de caráter completamente calculístico, análoga aos procedimentos matemáticos, que fosse independente da linguagem comum do mundo (Santos, 1963).

Leibniz influenciou seus contemporâneos e posteriormente seus sucessores através de seu projeto de desenvolvimento da lógica. Este projeto tentou criar uma linguagem universal baseada em um alfabeto do pensamento, uma espécie de cálculo universal para o raciocínio. Diante da complexidade da realidade física do mundo real sua tentativa fracassou; mas seus princípios foram retomados posteriormente.

No início do século XIX predominavam as correntes filosóficas formalista e idealista, cujas compreensões do mundo e da realidade eram baseadas na metafísica e no pensamento lógico puro, desconsiderando o aspecto real e a experiência concreta em suas concepções e explicações, como pode ser identificado na dialética Hegeliana (Spencer \& Barros, 1993).

A partir de meados do século XIX começam a surgir diversas tentativas de definição das teorias científicas a partir da lógica formal. Nesse sentido, as esperanças iniciais dos pensadores e teóricos eram de que as construções lógicas dos conceitos empíricos permitiriam o esclarecimento das evidências sensoriais 
das ciências e, com isso, o discurso sobre o mundo poderia tornar-se completamente racionalizado e objetivado (Spencer \& Barros, 1993).

A lógica simbólica teve grande desenvolvimento nesse período e não tardou em ser aplicada à descrição geral de diversas teorias e abordagens científicas (Spencer \& Barros, 1993), como atestam as obras de filósofos como Augustus De Morgan (1806-1871), George Boole (1815-1864), Götlob Frege (1848-1925) e Giuseppe Peano (1858-1932).

Em paralelo à aplicação da lógica e da matemática a áreas novas, puras e aplicadas da atividade acadêmica e tecnológica, ocorreu naquele momento a recriação de conhecimentos humanos e o surgimento de novas disciplinas. Foi a partir desse rico momento que se abriu a inter-relação das tradições lógica e filosófica com as ciências naturais modernas, como no caso das novas ciências da psicologia e da sociologia, por exemplo (Spencer \& Barros, 1993).

Por outro lado, na segunda metade do século XIX seguiu-se uma reação contra o formalismo e o idealismo dominantes, exigindo maior respeito à experiência e aos dados positivos reivindicados pelos novos campos de saber. Essa reação ganhou vida através da filosofia positivista de Auguste Comte (Aron, 2003).

O Positivismo de Comte, contrariando toda a tradição filosófica até então vigente, estabeleceu como princípio fundamental para o verdadeiro conhecimento a experimentação prática. Para Comte, somente à experimentação o investigador deve ater-se, ou seja, toda especulação acrítica, toda metafísica e toda teologia devem ser descartadas, pois não são capazes de garantir a razão (Aron, 2003; Comte, 1990). Comte, portanto, introduz um princípio de racionalidade na filosofia, até então dominada por uma razão metafísica.

Partindo de uma perspectiva positivista, Marx (1968), busca distinguir o método dialético de Hegel do seu próprio método dialético. Segundo o autor, a dialética idealista mostra-se criticável em seu aspecto racional, dado que a concepção positiva das coisas existentes passa a considerá-las uma configuração meramente transitória e limitada historicamente da vida social (Aron, 2003; Marx, 1968). Segundo Marx (1968), para Hegel o processo do pensamento, identificado com a idéia (ou Razão Absoluta), transformar-se-ia no sujeito; o real seria apenas uma materialização externa da idéia. O movimento do real seria, dessa forma, uma realidade derivada, já que o seu fundamento e a sua determinação se dariam na racionalidade das idéias. O homem histórico, portanto, seria apenas um instrumento do qual se valeria a idéia para se desenvolver (Aron, 2003; Marx, 1968).

Dessa forma, para Marx, a idéia não preexistiria ao real. A idéia seria o próprio real transposto e traduzido racionalmente no pensamento do homem. Marx, desse modo, contrapôs à dialética mistificada de Hegel a sua visão de dialética baseada 
no real. A proposição de Marx (a dialética materialista), se baseia na realidade histórica, buscando estabelecer o sentido da existência a partir da investigação preliminar do real (Aron, 2003; Marx, 1968).

Na mesma perspectiva fundamental do positivismo, o filósofo e matemático Charles Sanders Peirce (1839-1914) contestou no final do século XIX a noção de que os conceitos e intelecto humanos, sozinhos, seriam capazes de representar correta e completamente a realidade. A partir dessa idéia Peirce cunhou o termo pragmatismo para denotar a referência à prática, tomando as ações humanas e suas conseqüências como a base da mensuração da verdade, do valor etc. Para ele, as consequiências e a utilidade prática seriam componentes vitais de compreensão da realidade. Peirce concebia o pragmatismo, basicamente, como um método para racionalização de idéias, o qual envolvia a aplicação de métodos científicos no estudo de temas filosóficos (James, 2004).

A idéia do pragmatismo transposta para o campo da ciência não se refere meramente a um método científico, e sim a uma forma fundamental pela qual os homens se relacionam e se unem uns aos outros e ao mundo ao seu redor, constituindo formas sociais organizadas e com sentido. Em síntese, o pragmatismo se apóia na idéia de que somente através do esforço de organismos racionais atuando no ambiente é que os dados adquirem sentido. Na visão de Peirce a experiência prática seria determinante da racionalidade dos indivíduos.

A concepção pragmatista de Peirce foi continuada no início do século XX pelo filósofo e psicólogo norte-americano William James (1842-1910), que desenvolveu o conceito de pragmatismo, dando-lhe uma feição que ficou conhecida como empirismo radical (James, 2004; Schultz, 1991).

A concepção pragmatista de James constitui-se, a um só tempo, um método experimental aplicado ao discurso e uma teoria filosófica sobre a noção de verdade. James procurou, com este método, dotar a filosofia do mesmo instrumental empírico utilizado pelas ciências. Assim, propôs uma reestruturação da noção de verdade; esta passaria a ser compreendida como algo dinâmico, ou seja, o que é verdadeiro é o que pode satisfazer o problema proposto. Para o autor, o sentido das coisas parte do que funciona na experiência a partir de uma relação racional entre meta objetivada e curso de ação necessário (James, 2004).

Outro sucessor da idéia de pragmatismo foi o filósofo e educador John Dewey (1859-1952). Dewey combinou o pragmatismo filosófico e suas idéias pedagógicas progressistas e concebeu a experiência como algo que poderia produzir afirmações garantidas (warranted assertibility), ou seja, dever-se-ia observar a experiência — seja ela psíquica, histórica, real, ou de relação homem-meio — e a partir dela, dizer, diante de enunciados, se estes seriam garantidos ou não. A garantia (veracidade) seria dada, para cada enunciado, com as devidas especificações de seu uso e 
condições de validade, em uma relação baseada em arranjo racional de elementos presentes em dado contexto ou conjunto de variáveis (Schultz, 1991). Na visão de Dewey percebe-se que a racionalidade seria uma variável dependente e resultante de um conjunto de aspectos (regras e contextos) configurados momentaneamente.

Constata-se que a discussão filosófica sobre as bases da racionalidade humana foi marcada por um contínuo questionamento entre o campo das idéias e o campo da ação prática, gerando-se uma dicotomia na qual ora prevalecia a razão pura das idéias, ora prevalecia a ação prática no mundo. Disputavam as concepções de que a razão é um aspecto eminentemente intelectual, independente da experiência prática e, por outro, a concepção de que é a experiência prática que modela e determina os padrões de racionalidade.

Os preceitos filosóficos da lógica e do pragmatismo guardam um relacionamento estreito com a noção de racionalidade, fornecendo substratos teóricos e práticos que, de diferentes maneiras, influenciaram as concepções de racionalidade desenvolvidas nas ciências contemporâneas, podendo ser identificadas nitidamente nas idéias de autores como Weber, Mannheim e outros. Atualmente, surgem tentativas de se compreender ambos os elementos - pensamento e ação, ou, lógica e pragmática — dentro de uma perspectiva mais integradora.

Portanto, no desenvolvimento histórico da filosofia, as idéias de racionalidade e de razão foram estabelecidas em posições antagônicas, com a primeira procurando respeitar a experiência (pragmática), até mesmo para poder dominá-la, e a segunda procurando deduzi-la de leis gerais invariáveis (lógica), para além do tempo e do espaço. A partir do século XIX esse embate filosófico vai pender a favor da racionalidade, com a proposição do Positivismo de Comte, que impôs fronteiras à razão, ao evidenciar a presença da irracionalidade no mundo real e, em lugar de proclamar, em abstrato, a soberania da razão, tratou de tornar esse universo irracional o mais racional possível pelo trabalho constante e ininterrupto do entendimento e do ajuste, tarefa essa abraçada inicialmente por Weber (1994) e, no decorrer do século XX, por diversos teóricos e correntes de pensamento.

\section{Weber e o Conceito de Racionalidade}

A racionalidade pode ser entendida modernamente, a partir de Weber (1994), como aquilo que qualifica o sentido da ação social. Em outras palavras, pode ser entendida como a forma ou a orientação que a ação com sentido assume. Tal afirmativa, segundo Weber, pode ser entendida a partir da idéia de que o processo de racionalização assume seu lugar na vida social independentemente de outros fatores, de forma própria e em padrões pouco previsíveis. Dessa maneira, a 
racionalidade pode assumir diferentes proporções, com enfoques que variam conforme o padrão de ação adotado pelos indivíduos em determinado contexto sócio-histórico.

Ao discutir a ação social, Weber (1994) argumenta que esta pode ser orientada:

de modo racional referente a fins, por expectativas quanto ao comportamento de objetos do mundo exterior e de outras pessoas, utilizando estas expectativas como condições ou meios para alcançar fins próprios, ponderados e perseguidos racionalmente, com sucesso; de modo racional referente a valores, pela crença consciente no valor - ético, estético, religioso ou qualquer que seja sua interpretação - absoluto e inerente a determinado comportamento como tal, independentemente do resultado; de modo afetivo, especialmente emocional, por afetos ou estados emocionais atuais; de modo tradicional, por costume arraigado (p. 15).

Assim, de acordo com Weber (1994), o motivo ou razão de ser de dada ação e, conseqüientemente, de dada relação social, pode ser encontrado não somente na satisfação do interesse utilitário, mas na prática tradicional ou costumeira em que $\mathrm{o}$ ator se insere, na carga e teor dos valores que o ator recebeu no seu processo de socialização e que, diante de uma situação corriqueira, despertam sensos de obrigação, ou mesmo em manifestações emocionais pontuais, que têm mais sentido para o ator específico que nela se envolve e menos sentido para a coletividade dos atores.

Weber propôs também uma taxonomia das formas de racionalidade que, apesar de distintas umas das outras, se sobrepõem mutuamente. Trata-se das racionalidades prática, teórica, substantiva e formal (Ramos, 1983). A racionalidade prática está relacionada com a visão e juízo do indivíduo sobre uma prática assumida. São as ações do cotidiano que darão o direcionamento do comportamento adotado. Rege-se por um comportamento puramente calculista e individualista, unindo os interesses úteis e verdadeiros do agente da ação.

A racionalidade teórica envolve o domínio da realidade através da construção de conceitos abstratos precisos em detrimento da ação. Isto implica que a condução à ação não precisa ocorrer necessariamente. A operacionalização deste tipo de racionalidade estaria ligada a julgamentos internos que determinam o controle e inibição de uma ação motivadora de um comportamento.

A racionalidade substantiva refere-se ao direcionamento de ordens de ação sob determinados padrões que levam em consideração a contextualização do indivíduo, sem contudo ter como base somente o cálculo dos fins. Dessa forma, cada ponto de vista implica uma configuração identificável de valores que determina a direção de um processo de racionalização subseqüente. Esses valores adquirem 
racionalidade por seu status como consistentes postulados de valores. Assim, diferentes facetas da vida defendem seus próprios postulados de valores como racionais e rotulam as outras facetas como irracionais. Além do mais, a racionalidade substantiva é orientada por valores sociais e está em conformidade com pressupostos sociais.

A racionalidade formal - chamada por Mannheim (1973) de racionalidade funcional — configura a articulação ou relação entre as ações para que os objetivos predeterminados sejam atingidos. A racionalidade é orientada então pelos objetivos a serem atingidos, e o seu atendimento é o determinante da racionalidade. Nesta lógica prevalece a relação entre meios e fins. Nesse tipo de racionalidade não é questionada a qualidade intrínseca das ações, mas seu maior ou menor concurso, numa série de outros, para atingir um determinado fim preestabelecido, independentemente do conteúdo que possam ter as ações em questão.

Observa-se que Weber (1994) não distingue a racionalidade formal do indivíduo de sua racionalidade substantiva. $\mathrm{O}$ homem possui as duas racionalidades e utilizase da racionalidade formal, quando os fins justificam sua conduta.

Embora nem todas as formas de orientação da ação com sentido possam ser consideradas, por si mesmas, racionais, na acepção lógica que o termo prescreve, a ação racional utilitária, ou seja, aquela que se orienta logicamente para a consecução consciente de um fim - através do cálculo utilitário de conseqüências - deve ser vista somente como mais uma entre outras orientações possíveis da ação com sentido (Weber, 1994).

Pode-se aqui deduzir um elemento essencial que caracteriza a racionalidade: a subordinação dos meios aos fins, expressa pelo cálculo utilitário empreendido pelos atores com vista da obtenção otimizada - eficiente e eficaz — do objetivo, meta, ou projeto futuro externo a eles próprios.

A ação racional orientada a fins, assim como as demais orientações que a ação com sentido pode adquirir, é, em primeiro lugar, uma ação com sentido percebido pelo ator. Desta forma combina, na percepção do sentido, elementos intrínsecos e extrínsecos ao indivíduo.

A ação racional referente a fins depende justamente da percepção de sentido por parte dos atores (Weber, 1994). Esta percepção é, em certa medida, construída pelo contexto social, histórico e simbólico sob o qual se encontram tais atores. Em outras palavras, a ação instrumental possui sentido para o ator na medida em que este foi socializado, educado ou cresceu em um contexto social e histórico que valoriza a ação estratégica, calculista e movida por objetivos. Assim, a ação racional depende também da existência de certos significados sociais compartilhados e não somente da iniciativa voluntária e autônoma de um indivíduo, 
ponto de vista esse compartilhado por Mannheim (1973), que também defende a existência de uma racionalidade funcional, modelada pela realidade social em que o homem está inserto.

Para Weber (1994), a ascensão da racionalidade por fins, como orientação da ação com sentido, está relacionada a uma mudança maior no sistema de referências sociais caracterizada pelo desencantamento do mundo. Tal desencantamento pode ser entendido como o processo através do qual os valores tradicionais e religiosos, que historicamente orientavam a ação das pessoas em sociedade, vão dando progressivamente lugar aos valores racionais, pragmáticos e objetivos na orientação de tais ações.

Assim, Weber (1994) considera a racionalidade formal como um modelo de conduta humana que pertence, particularmente, a um momento específico e recente na história da humanidade, caracterizado de forma mais intensa a partir do desenvolvimento do capitalismo no Ocidente, e que pode hoje ser encontrado predominantemente em uma esfera também específica das relações sociais, a esfera das organizações burocráticas modernas.

\section{Racionalidade e Burocracia}

$\mathrm{Na}$ ótica weberiana a racionalidade foi tomada como o elemento diferenciador entre as organizações racionais - burocráticas - e os outros arranjos ou estruturas sociais existentes (Gerth \& Mills, 2002).

O sistema burocrático pressupõe a previsibilidade do comportamento dos funcionários (Gerth \& Mills, 2002; Motta \& Pereira, 1986). Dentro do marco teórico racionalista, somente através da previsibilidade da ação humana é que se podem estabelecer metas e planejar a ação organizacional. Nessa concepção, os aspectos subjetivos e afetivos do comportamento humano apresentavam-se como disfuncionais à racionalidade, dada a sua imprevisibilidade e irracionalidade.

Na visão de Weber era necessário retirar a arbitrariedade e a irracionalidade do funcionamento das organizações, devendo prevalecer o argumento técnico e racional, principalmente dentro da sociedade moderna, na qual eram multiplicadas em quantidade e complexidade as empresas, exigindo-se, cada vez mais, a precisão, a velocidade, a continuidade e a economia de recursos em sua administração (Gerth \& Mills, 2002). Além disso, Weber concebe a burocracia como o instrumento racional máximo da sociedade; por isso mesmo, detentora do poder social a serviço das cúpulas diretivas burocráticas, para ordenar a massa social irracional e desorganizada (Gerth \& Mills, 2002; Motta \& Pereira, 1986). Nesse sentido, 
Weber propõe uma separação entre a elite técnico-burocrática e a sociedade em geral, concebida como inferior, por não possuir os elementos racionais e técnicos que a conduzissem à objetividade (Gerth \& Mills, 2002).

Observa-se que a burocracia de Weber compõe-se de um conjunto de dispositivos que envolvem a definição de normas administrativas baseadas em áreas formais e oficiais de jurisdição, a distribuição das atividades organizacionais de forma fixa, pela delimitação de autoridade dos funcionários — assim como de sua hierarquia de subordinação funcional - a metodização e normatização da execução das atividades, a utilização de documentação escrita, devidamente registrada e arquivada, a especialização técnica dos indivíduos nas regras e procedimentos exigidos pelos cargos. Envolve, além do mais, um significativo grau de formalidade e impessoalidade nas relações entre os indivíduos, concebendo-se cada funcionário como um executor de trabalho completamente planejado, organizado e compartimentado. A decisão e os níveis de autonomia são estabelecidos em função das regras, normas e cargos e, não, em função de interesses ou opiniões das pessoas. Busca-se então, através da burocracia, a eliminação das disfunções produtivas e administrativas da sociedade e suas organizações, por meio do controle do comportamento dos indivíduos, a partir de um arranjo social de funcionamento, independentemente dos interesses e afetos humanos; estes devem ser erradicados, para que o sistema funcione continuamente e sem erros (Gerth \& Mills, 2002; Motta \& Pereira, 1986).

Com o crescimento e sofisticação, tanto da sociedade em geral, quanto das organizações públicas e privadas, observa-se que o sistema racional burocrático passou a ser um padrão fundamental e indispensável ao mundo atual (Aron, 2003). Como afirma Mannheim (1973), nossa sociedade industrial burocrática está sendo modelada por expectativas características de uma civilização urbana e industrial, onde o sucesso é ponto objetivo e perseguido por todos os membros. O indivíduo está sempre preocupado com a racionalização dos seus métodos, para que o destino não seja o responsável por seu sucesso ou fracasso, posição esta alicerçada no paradigma da existência racionalizada, presente no estágio atual de desenvolvimento humano.

Segundo Weber (1994), o indivíduo inserido em uma organização burocrática é determinado pela sua ação, a qual, por sua vez, é orientada para a consecução dos objetivos da organização em que trabalha. A razão desta ação se restringirá à ação social no que tange aos fins, ou seja, o agente da ação escolhe seus objetivos, e tenta alcançá-los de uma forma que ele considera racional. Assim, a racionalidade formal geralmente está relacionada a esferas de vida e estruturas de dominação que adquirem limites específicos e delineados somente com a industrialização, mais especificamente por meio das esferas econômicas, legal e científica, e a forma burocrática de dominação. É a racionalidade meio-fim, 
orientada por regras, regulamentos e normas, que não considera aspectos pessoais. Neste sentido, os próprios procedimentos científicos são também racionais.

Observa-se, entretanto, que o incremento da racionalização formal das burocracias modernas traz conseqüências para as organizações e indivíduos, que devem receber uma atenção especial. Segundo Mannheim (1973), o incremento da racionalização funcional (formal) das burocracias modernas gera o problema da anulação do indivíduo, devendo as organizações orientar-se para o resguardo de um mínimo de iniciativa individual ou racionalidade substantiva.

Mouzelis (1975) compartilha o mesmo ponto de vista e salienta a preocupação em resguardar o espaço e a iniciativa do indivíduo, permitindo-lhe um espaço de pensamento e ação individual no contexto das organizações. Segundo o autor as organizações devem preocupar-se "não como tornar as pessoas mais felizes e cooperadoras com a administração, mas somente tentar evitar que cheguem a converter-se nos felizes autômatos de um 'admirável mundo novo'" (Mouzelis, 1975, p. 187).

Deve-se, dessa forma, considerar a necessidade de se perceber e evitar o extremo distanciamento entre a racionalidade formal ou funcional da racionalidade intrínseca do ser humano, distanciamento esse estimulado pela ordem social atual e pelas estruturas burocráticas modernas, que transformam o indivíduo em mero autômato obediente à lógica produtiva, baseado em relacionamento meramente instrumental.

\section{As Organizações e os Limites Cognitivos da Racionalidade}

No contexto das organizações burocráticas a racionalidade exige que o indivíduo ajuste seu comportamento a um sistema integrado para a sua tomada de decisão, através de uma visão panorâmica das alternativas comportamentais disponíveis, da consideração do conjunto de conseqüências relacionadas às alternativas e, da escolha de uma alternativa entre as disponíveis. Entretanto, no mundo real, a racionalidade plena e objetiva não é efetivamente alcançada em função da incapacidade humana de conceber todos os conhecimentos em cada linha de conduta possível. Além disso, não é viável levar em consideração a totalidade das possíveis alternativas; somente é possível o acesso a uma parcela dessas alternativas, como apontam Simon (1965) e March e Simon (1972).

Assim, a racionalidade do indivíduo é limitada pelo nível de conhecimento que ele tem acerca das coisas. Daí o comportamento individual ocorrer baseado em premissas ou pressupostos sobre as questões que se colocam, premissas estas que nortearão a linha de conduta e a tomada de decisão na organização. Deste modo, as variações de comportamento possíveis estarão necessariamente 
condicionadas pelos limites dados pelas premissas ou pressupostos. Além do mais, mesmo em situações em que se tenha um conhecimento maior das conseqüências de uma escolha, a sua antecipação dificilmente produzirá resultados mais efetivos, dado que as preferências mudam em função dos valores predominantes, fazendo com que a avaliação premeditada seja inexata; ela vai sofrendo variações de valor, desde a consideração inicial até a execução prática.

Há de se considerar também que cada alternativa de linha de conduta possui consequiências distintas e, quando o indivíduo se depara com a necessidade de escolher uma entre várias linhas de conduta, tal situação adquire tamanha complexidade, que faz com que somente algumas dessas conseqüências sejam efetivamente reconhecidas por ele como desdobramentos de uma decisão; muitas delas provavelmente serão simplesmente ignoradas.

A racionalidade humana opera, pois, dentro dos limites de um meio ambiente psicológico. Este ambiente impõe ao indivíduo, a partir de pressupostos dados, uma seleção dos fatores sobre os quais deve basear suas decisões, como pode ser visto na organização burocrática.

Simon (1965), nessa linha de pensamento, partiu do princípio de que é possível isolar da realidade uma situação que contenha apenas um número limitado de variáveis e uma série limitada de consequiências relacionadas. Desta forma, no contexto das organizações faz-se um recorte na realidade, na tentativa de focalizar uma questão a partir de uma contextualização restrita, que permita a identificação de desdobramentos mais ou menos previsíveis; o indivíduo realiza suas opções baseado em uma imagem simplificada da situação, considerando apenas os fatores que julga relevantes e fundamentais, usando a concisão exigida pela racionalidade.

Observa-se então que as organizações buscam influenciar a racionalidade do comportamento dos indivíduos, a fim de assegurar a coordenação das atividades e sua eficiência, uma vez que esta depende da concatenação das atividades dos membros daquele grupo social e não somente da eficiência de indivíduos isolados.

As demandas da sociedade e as necessidades do indivíduo requerem que ele esteja para os outros tanto quanto para si mesmo, ou seja, que os outros sejam considerados tanto como fins, quanto meios para tal indivíduo. Desta forma, certo equilíbrio racional entre os fins e os meios deve ser entendido, para que o indivíduo possa exercer papel maior no entendimento de si mesmo e de sua atuação social. Como propõe Arrow (1974), ocorre uma tensão entre a ação individual e a da consciência social. Assim, a racionalidade relaciona-se com os fins e os meios e seu inter-relacionamento, ou seja, a todo o momento o indivíduo é colocado diante de um conflito entre seus desejos individuais e as demandas da sociedade, não ocorrendo uma integração plena entre o contexto social e o contexto individual. Devido a isso, as sociedades em sua evolução desenvolveram acordos implícitos 
para certos tipos de consideração pelos outros, acordos esses que são essenciais para a sobrevivência da sociedade ou, pelo menos, para racionalizar as relações sociais e contribuir para a eficiência de seu funcionamento. Percebe-se que no âmbito das organizações burocráticas estas fazem uso desses acordos ao normatizarem racionalmente o trabalho, revalidando, no interior da organização, códigos de conduta acordados socialmente.

Na visão de Mannheim (1973) existiriam dois tipos de racionalidade: a racionalidade funcional - típica das organizações burocráticas e voltadas para os fins a serem alcançados - e a racionalidade substancial — baseada na consciência individual da relação entre os fatos, voltada para a compreensão da realidade e busca da liberdade. Tal diferenciação, em última análise, relativizou a idéia de irracionalidade no sentido weberiano. Por outro lado, o próprio Mannheim aponta o desenvolvimento crescente da racionalidade funcional em face da expansão das organizações burocrática complexas no mundo moderno, obrigando os indivíduos a adotarem padrões de auto-racionalização, por causa de sua necessidade de emprego e se conformarem com as complexas feições e exigências da organização do trabalho nas empresas modernas (Mannheim, 1973).

Além do mais, o espaço privado e o espaço organizacional são percebidos agora não como antagônicos, sendo o espaço privado marcado pela irracionalidade e ausência de objetividade - o mundo disfuncional — e o espaço organizacional como o espaço da razão e da objetividade - o mundo funcional - mas como espaços distintos. Haveria então uma racionalidade organizacional e uma racionalidade pessoal, e a conseqüente irredutibilidade do indivíduo à razão da organização. A partir dessa constatação, a funcionalidade organizacional é obtida, agora, pela integração do indivíduo à organização mediante a calculada autoracionalização da conduta individual, ou seja, os indivíduos precisam controlar seus impulsos, valores, ideologias, crenças e preferências, para se adequarem à crescente racionalidade funcional exigida pelas organizações modernas. Observase aqui como pressuposto a ética da responsabilidade, como bem observa Ramos (1983), produzindo o ajustamento do homem ao trabalho e às normas.

\section{Racionalidade e Legitimidade nas Organizações}

Observa-se que a pura e simples imposição de regras e normas racionalmente constituídas não garante a adesão dos indivíduos a elas. Tal consideração levou Weber a estabelecer mecanismos de condicionamento social para legitimar o sistema burocrático e produzir a coesão entre o mando da norma racional e a sua obediência pelo indivíduo (Gerth \& Mills, 2002). Como demonstra Etzioni (1967), quando o exercício do poder é considerado legítimo pelos indivíduos submetidos a 
ele, a submissão das pessoas tende a ser mais profunda e funcional. Segundo esta linha de pensamento, o subordinado incorpora as regras organizacionais, passando a perceber a disciplina imposta pelas normas como menos alienadora, como algo pertencente a si mesmo. Isso faz com que o indivíduo continue a seguir as regras, mesmo nos casos em que o controle e a disciplina, ou seja, o poder, estiver ausente.

Dessa forma, o sistema burocrático legitima-se pelo uso do poder racionallegal (Gerth \& Mills, 2002; Motta \& Pereira, 1986), operacionalizado através da utilização de mecanismos como a exigência de qualificação técnica — que estimula a idéia de meritocracia, a definição de cargos específicos — os quais são ocupados hierarquicamente em uma carreira lógica predefinida, a partir de uma política de estabilidade no emprego até que se atinja a aposentadoria, e a valorização da antigüidade e experiência profissional como fatores de ascensão no status organizacional e crescimento salarial etc. Tais aspectos se organizam de forma a produzir o compartilhamento de interesses dos funcionários, dando-lhes uma identidade comum. Como salienta Merton (1968), tais elementos estimulam o desenvolvimento de forte ligação grupal que se destina a proteger os padrões do grupo, não contra o próprio sistema burocrático, e sim contra agentes externos à organização que ameacem tal ordem. Consegue-se com isso a criação de vínculos interpessoais que reduzem os conflitos internos, aumentando a coesão dos funcionários e, além disso, são criados elos que estimulam a defesa e manutenção das próprias regras e normas, dando continuidade à racionalidade inerente àquela organização (Merton, 1968).

De outra forma, observa-se que as grandes organizações passaram a constituir parte relevante do ambiente, influenciando outras organizações e introduzindo elementos que acabam, em última instância, por alterar o próprio ambiente. Essa situação passou a exigir de tais organizações habilidades em interagir dinamicamente com o ambiente em que se inserem, buscando lidar com mudanças e exigências de adaptação (Perrow, 1972).

Segundo Perrow (1972), as grandes organizações dependem de contingências sociais e culturais em transformação, de forma que as sociedades determinam os padrões de afluxos de elementos para elas, facilitando ou dificultando a entrada de recursos necessários ao seu funcionamento. Desta forma, uma das atribuições implícitas das organizações é criar autenticidade para seus produtos legitimandoos, ou seja, produzindo uma racionalidade que recubra seus produtos e sua existência com significados socialmente aceitos e, a partir daí, garantam a renovação do afluxo de recursos pela aceitação daquela racionalidade como legítima e lógica. Assim, o sucesso e sobrevivência das organizações dependem de sua capacidade em neutralizar a ação competitiva e de sua habilidade em fazer uso de uma racionalidade que dê sentido aos agentes que influenciam as suas fontes de recursos. 
Dentro da perspectiva institucionalista, Powell e DiMaggio (1999) afirmam que o novo institucionalismo, em teoria das organizações e na sociologia, inclui uma rejeição dos modelos baseados no ator racional. Interessa-se por propriedades de unidades de análise supra-individual e volta seu olhar para explicações cognitivas e culturais. Enfatiza, desse modo, o relacionamento entre organizações e seu ambiente, enfatizando que é o efeito desse elemento no desenho organizacional que determina sua configuração e não uma racionalidade intrínseca à própria organização.

Partindo das premissas de Powell e DiMaggio, os autores Tolbert e Zucker (1999) salientam que as estruturas formais possuem, ao mesmo tempo, propriedades simbólicas e capacidade de gerar uma ação, ou seja, possuem significados socialmente compartilhados, assim como são capazes de atingir determinados objetivos concretos. Isso implica que a estrutura formal pode existir independentemente da situação de controle e coordenação racional dos indivíduos na organização. Da mesma forma, a avaliação social das organizações está relacionada à sua estrutura formal e não aos seus resultados operativos, ou seja, as organizações poderiam sobreviver, apesar de apresentarem baixo desempenho, o que, dentro de uma perspectiva racional pura, estaria em completo desacordo.

Segundo Berger e Luckmann (1996), a vida cotidiana apresenta-se aos homens como realidade racionalmente ordenada, composta por uma série de objetos designados como tal antes da sua existência como indivíduos. Os fenômenos sociais estão previamente dispostos em padrões que parecem independentes da apreensão que cada um, individualmente, possa ter deles. À medida que a realidade da vida cotidiana é compartilhada com outros seres humanos, o indivíduo percebe a correspondência entre os significados que atribui a um objeto e os significados atribuídos por seus semelhantes, ou seja, existe a produção de um conhecimento sobre a realidade da interação social. Por sua vez, ao legitimar e dar consistência a um conjunto de significados integrados em um universo simbólico, expresso em regras e sistemas de crenças, o homem apreende a realidade, em processo dialético entre idéias e padrões sociais. Como já observava Weber (1994), sob essa ótica não há resposta mecânica aos estímulos, mas uma formação da resposta após a interpretação do estímulo, ou seja, não ocorre racionalidade automática; ao contrário, o sentido precisa ser construído.

No ambiente organizacional, esse processo conduz ao surgimento dos chamados mitos racionais. Em outras palavras, as características burocráticas tornaram-se um conjunto de preceitos institucionalizados na sociedade moderna, uma concepção socialmente construída e legitimada, acerca da maneira mais eficaz e racional de funcionamento das organizações (Powell \& Dimaggio, 1999). Conseqüentemente, a forma das organizações modernas se conserva a partir de um sistema de crenças ou mitos racionais, o qual enfatiza a relevância 
da própria racionalidade. Desse modo, para o público em geral, a legitimidade das organizações está associada à sua habilidade em agir de modo racional (Powell \& Dimaggio, 1999).

Observa-se, portanto, que a partir da disseminação do próprio sentido da racionalidade como expressão de um sentido lógico maior, as organizações buscam transmitir uma imagem organizacional coesa, unificada e consensual. Entretanto percebe-se que tal racionalidade se relaciona mais a um discurso socialmente elaborado para a transmissão de uma idéia de controle racional organizacional do que a presença e ação efetiva de uma racionalidade intrínseca à organização.

Assim, a estrutura é organizada em função da necessidade de legitimar a própria organização. Por trás da aparente racionalidade esconde-se uma tecnologia a serviço do capital que precisa ser legitimada, utilizando-se de relatos racionalizantes, que têm em sua origem primordial diversos aspectos simbólicos e míticos que produzem ou orientam determinados sentidos.

\section{Racionalidade e Teoria Crítica}

Autores como Habermas, Horkheimer e Marcuse, entre outros, podem ser considerados como pensadores que consideraram a racionalidade sob uma perspectiva diferenciada. Sua percepção das mudanças do mundo contemporâneo permitiu que reconsiderassem o conceito de racionalidade, introduzindo óticas mais ampliadas para a idéia de razão e racionalidade.

Na perspectiva de Habermas (1987b) com o processo de modernização social passou a prevalecer nas sociedades industriais contemporâneas a racionalidade formal, definida pela organização de meios adequados para atingir determinados fins ou pela escolha entre alternativas estratégicas com vistas à consecução de objetivos. Tal racionalização na sociedade moderna caracteriza-se pela ampliação crescente de esferas sociais que ficam submetidas a critérios técnicos de decisão racional, isto é, a critérios de adequação e organização de meios em relação a determinados fins; o planejamento e o cálculo tornaram-se, cada vez mais, partes integrantes de procedimentos que envolvem questões administrativas.

Segundo Habermas (1987a), na medida em que a racionalidade formal da ciência e da técnica penetra nas esferas institucionais da sociedade, transforma as próprias instituições, de tal modo que as questões referentes às decisões racionais baseadas em valores, ou seja, em necessidades sociais e interesses globais, que se situam no plano da interação, são afastadas do âmbito da reflexão e da discussão. Segundo o autor a racionalidade formal, na trajetória de ampliação de seu campo de atuação, 
substituiu, de forma crescente, o espaço da interação comunicativa que havia anteriormente no âmbito das decisões práticas que diziam respeito à comunidade. Dessa forma, são desarticuladas as antigas formas ideológicas de legitimação das relações sociais de poder. Com esse tipo de racionalidade não se questiona se as normas institucionais vigentes são justas ou não, mas somente se são eficazes, isto é, se os meios são adequados aos fins propostos, ficando a questão dos valores éticos e políticos submetida a interesses instrumentais e reduzida à discussão de problemas técnicos.

Observa-se que Habermas não se posiciona radicalmente contra a racionalidade formal e da técnica em si mesmas, mas, posiciona-se radicalmente contra a universalização da ciência e da técnica, isto é, contra a penetração da racionalidade científica, formal, em esferas de decisão social (Habermas, 1987b). Diante desta constatação, a teoria de Habermas repousa na concepção de coexistência de duas formas de racionalidade distintas: a) a atividade racional em relação a um fim, orientada na direção do sucesso, de natureza instrumental ou estratégica e que corresponde à reprodução material do mundo vivido, garantido por sistemas funcionais como as organizações e o Estado; e b) a atividade racional comunicacional, que não é coordenada por cálculos de sucesso egocêntricos, mas pela necessidade de intercompreensão dos indivíduos, correspondendo à reprodução simbólica do mundo vivido, baseada na compreensão mútua e no consenso através de meios linguiísticos, como os produzidos na família e na esfera pública (Habermas, 1987a).

Habermas propõe, portanto, um modelo ideal de ação comunicativa em que as pessoas interagem e, através da linguagem, criam sentidos sociais compartilhados que passam a orientar sua racionalidade, independentemente da racionalidade formal e técnica.

Já na perspectiva de Horkheimer (2002), a razão pensada nos moldes do Iluminismo deve ser criticada e, apesar de não negá-la, afirma que a construção histórica foi determinante para a concepção da crise da racionalidade na era contemporânea. Segundo o autor, a razão subjetiva e a razão objetiva devem ser comparadas com os conceitos de racionalidade formal — funcional — e substantiva desenvolvidos por Weber. Horkheimer relaciona a razão subjetiva ou funcional com a possibilidade de se poder calcular as probabilidades e, consequientemente, coordenar os meios convenientes a um dado fim. Já a razão objetiva ou substantiva é relacionada com a idéia do bem maior e com a maneira de atingi-lo.

Considerando-se ainda a perspectiva de Marcuse (1975), o autor parte da idéia de que as mudanças nos modos e nas relações de produção - em função da crescente mecanização e automatização da vida social — devem possibilitar o surgimento de nova forma histórica da realidade, uma vez que, sem a necessidade do trabalho, todos os bens materiais e intelectuais serviriam ao desenvolvimento 
das potencialidades humanas. Essa nova condição histórica produziria uma forma de racionalidade sensível, que o autor caracteriza e define como racionalidade do prazer. Essa racionalidade se opõe ao moderno conceito de racionalidade instrumental da sociedade capitalista, que se fundamenta na razão formal.

Segundo Marcuse (1975), a racionalidade do mundo ocidental é uma racionalidade técnica, repressiva, fundamentada numa razão que visa coordenar os meios com os fins, buscando apenas a operação e o procedimento eficaz na exploração e controles da natureza e dos homens. Essa razão abandonou os ideais iluministas de liberdade, igualdade e fraternidade, não tendo mais a preocupação com a felicidade humana, mas sim com o capital.

A racionalidade do prazer de Marcuse (1975) surge como um desdobramento dialético da racionalidade instrumental. Nesse sentido, o autor propõe a idéia de que a mudança na base material da sociedade deve mudar a forma da realidade. Se a forma da realidade é o da racionalidade instrumental, com o fim da sociedade do trabalho deve surgir uma nova racionalidade sensível. Nesta nova racionalidade o trabalho seria organizado tendo em vista a economia espaciotemporal para o desenvolvimento integral do indivíduo. Seria um novo mundo estético, onde o trabalho seria lúdico e prazeroso. Todas as esferas da vida social seriam organizadas de tal forma, que propiciariam o pleno desenvolvimento do indivíduo e a fruição do prazer. Nesta nova racionalidade do prazer surgiria contra uma concepção de indivíduo como logos (razão), a noção de indivíduo como eros (amor).

\section{Considerações Finais}

O conceito de racionalidade é um conceito multifacetado que traz implicações teóricas e práticas que não permitem a adoção de uma abordagem conclusiva. Trata-se de um conceito de significativa relevância na teoria das organizações, mas que, ao mesmo tempo, não permite delimitação precisa dos fenômenos envolvidos e relacionados a ele.

Inicialmente, ao se considerar a influência dos preceitos filosóficos relacionados às concepções de pensamento (lógica) e ação (pragmática) como balizadores da noção de racionalidade, observa-se que os autores contemporâneos sofreram as mesmas inquietações que os filósofos tiveram, ao tentarem delimitar as fronteiras entre idéia e experimentação e suas relações com a razão humana. Percebe-se que são conceitos extremamente interligados e uma teoria que considerasse apenas um desses aspectos tornaria frágil qualquer discussão.

No mundo contemporâneo a noção de racionalidade foi incorporada e 
formalizada por Weber a partir de seu conceito de burocracia. Não se pode negar que os princípios racionais burocráticos são indispensáveis à vida social moderna; entretanto a tentativa weberiana de erradicar os elementos irracionais e disfuncionais da sociedade e das organizações, se chocou, entre outras coisas, com a própria limitação humana em agir e utilizar a racionalidade. Nesse sentido são de relevância significativa a contribuição de Simon (1965) e March e Simon (1972) à compreensão de que a irracionalidade no sentido weberiano não poderia ser excluída, devendo as organizações não só consideraram as restrições ao exercício da racionalidade pelos agentes em temos de suas capacidades cognitivas, como também precisavam administrar tal limitação.

Outro ponto de destaque refere-se à idéia de racionalidade procedimental desenvolvida por Simon, a qual enfatiza a dificuldade das teorias baseadas no homem racional em lidar com situações de incerteza. Assim, na medida em que as restrições à racionalidade são admitidas pela teoria, o comportamento passa a ser colocado como fortemente dependente tanto do contexto em que ocorre quanto das características psicológicas do indivíduo, tornando-se uma racionalidade externa à própria lógica da norma e, mais uma vez, entram em choque os limites ente aspectos internos e externos na relação do homem com a racionalidade.

Percebe-se, então, que as organizações, para administrarem os limites cognitivos de seus membros, buscam racionalizar o processo de escolha das linhas de conduta das pessoas, começando pelo controle dos estímulos que fundamentam tal processo. Desta forma impõem, inicialmente, certos limites através da definição de políticas. Depois são estabelecidos mecanismos para dirigir a atenção e canalizar as informações e conhecimentos para que se conformem aos limites impostos por essas políticas. Finalmente, são executadas ações e decisões diárias limitadas ao espaço delineado pela burocracia estabelecida, delimitando a abrangência da própria racionalidade no meio organizacional.

Além do mais, observa-se que as organizações funcionam mediante a incorporação de orientações previamente definidas e racionalizadas na sociedade, as quais contribuem para a legitimação das suas atividades e para a sua sobrevivência, independentemente da eficiência e da demanda da sua produção (Powell \& Dimaggio, 1999). Dessa forma, programas e tecnologias são adotados nas organizações por força de pressões contextuais, refletindo regras e significados fixados por estruturas construídas e institucionalizadas na sociedade.

Há de se considerar que a racionalidade, mais do que orientar a compreensão cognitiva dos indivíduos e organizar a vida humana na sociedade e nas organizações, através de normas racionalmente desenhadas, desempenha papel relevante na justificativa, na legitimação e, principalmente, na conformação dos indivíduos à vida nas coletividades organizacionais, produzindo uma lógica que é interiorizada 
pelos próprios indivíduos em conformidade com as normas organizacionais próprias daquele sistema social, produzindo um sentido compartilhado por todos os membros.

Finalmente, deve-se considerar a relevância dos autores da teoria crítica, que representam uma expressão mais contemporânea da racionalidade. Essa perspectiva surge como crítica social a partir da visão de autores como Habermas, Horkheimer e Marcuse, que constataram que a promessa iluminista da libertação pela razão se viu comprometida pela maneira como o racionalismo se operacionalizou, sob forma de racionalidade instrumental, erodindo a possibilidade da emancipação humana. Na visão desses autores, o sentido da vida humana, especialmente em relação ao trabalho no mundo capitalista, não deve ser estruturado somente a partir de uma racionalidade funcional, mas a partir de uma ação compartilhada entre os indivíduos e grupos que busque o alcance de um bem maior social e a introdução de uma base lúdica e de prazer na relação do homem com a sociedade e com o trabalho.

\section{Artigo recebido em 14.11.2006. Aprovado em 20.11.2007.}

\section{Referencias Bibliográficas}

Aron, R. (2003).

As etapas do pensamento sociológico. São Paulo: Martins Fontes.

Arrow, K. J. (1974).

The limits of organization. New York: WW Norton.

Berger, P. L., \&

Luckmann, T. (1996).

A construção social da realidade: tratado de sociologia do conhecimento. Petrópolis: Vozes.

Comte, A. (1990).

Discurso sobre o espírito positivo. São Paulo: Martins Fontes.

Etzioni, A. (1967).

Organizações modernas. São Paulo: Pioneira.
Gerth, H. H., \&

Mills, C. W. (2002).

Ensaios de sociologia (5a ed.). Rio de Janeiro: LTC.

Habermas, J. (1987a).

Teoría de la acción comunicativa I: racionalidad de la acción y racionalización social. Madri: Taurus.

Habermas, J. (1987b).

Teoria de la acción comunicativa II: crítica de la razón funcionalista. Madri: Taurus.

Horkheimer, M. (2002).

Eclipse da razão. São Paulo: Centauro. 
James, W. (2004).

Pragmatismo. São Paulo: Martin Claret.

Luce, J. V. (1994).

Curso de filosofia grega: do séc. VI a.C. ao séc. III d.C. Rio de Janeiro: Jorge Zahar.

Mannheim, K. (1973).

Diagnóstico de nosso tempo. Rio de Janeiro: Zahar.

March, J. G., \&

Simon, H. A. (1972).

Teoria das organizações. Rio de Janeiro: FGV.

Marcuse, H. (1975).

Eros e civilização. Rio de Janeiro: Zahar.

Marx, K. (1968).

O capital (Vol. 1). Rio de Janeiro: Civilização Brasileira.

Merton, R. K. (1968).

Sociologia: teoria e estrutura. São Paulo: Mestre Jou.

Motta, F. C. P., \&

Pereira, L. C. B. (1986). Introdução à organização burocrática. São Paulo: Brasiliense.

Mouzelis, N. P. (1975).

Organización y burocracia. Barcelona: Ediciones Península.

Perrow, C. (1972).

Sociología de las organizaciones. Madrid: McGraw-Hill.
Powell, W. W., \&

Dimaggio, P. J. (Orgs.). (1999).

El nuevo institucionalismo en el análisis organizacional. México: Fondo de Cultura Econômica.

Ramos, G. (1983).

Administração e contexto brasileiro: esboço de uma teoria geral da administração. Rio de Janeiro: FGV.

Santos, M. F. (1963).

Dicionário de filosofia e ciências culturais. São Paulo: Maltese.

Schultz, D. (1991).

História da psicologia moderna. São Paulo: Cultrix.

Simon, H. A. (1965).

Comportamento administrativo: estudo dos processos decisórios nas organizações administrativas. Rio de Janeiro: FGV.

Spencer, R., \&

Barros, M. (1993).

Razão e racionalidade: ensaios de filosofia. São Paulo: TA Queiroz.

Tolbert, P., \&

Zucker, L. G. (1999).

A institucionalização da teoria institucional. In S. Clegg, C. Hardy, \& W. R. Nord (Eds.). Handbook de estudos organizacionais (Vol. 1, pp. 196-219). São Paulo: Atlas.

Weber, M. (1994).

Economia e sociedade (Vol. 1). Brasília: UNB. 